CARDIOLOGY

\title{
The Right Ventricle in Health and Disease: Insights into Physiology, Pathophysiology and Diagnostic Management
}

\author{
Stavros Apostolakis Stavros Konstantinides \\ Department of Cardiology, Democritus University of Thrace, Alexandroupolis, Greece
}

\section{Key Words}

Right ventricle $\cdot$ Physiology $\cdot$ Pathophysiology $\cdot$ Heart failure

\begin{abstract}
Until recently, the right ventricle (RV) received little attention in adult patients with congenital heart disease and even less attention in the setting of acquired heart failure. However, in the last two decades, our perspective towards the right side of the heart has begun to change. Advances in imaging modalities have permitted the accurate study of RV physiology and made it apparent that RV function is an important determinant of prognosis in heart failure irrespective of the underlying etiology. This article summarizes the existing data on the unique anatomical and physiological features of the RV. The hemodynamic conditions and cellular and biochemical pathways that lead to right heart failure are presented. Moreover, the imaging modalities that aid in the assessment of RV structure and function are described and the importance of the diagnostic and prognostic information they provide is discussed.

Copyright $\odot 2012$ S. Karger AG, Basel
\end{abstract}

\section{Introduction}

In 1616, the English physician Sir William Harvey first described the physiology of the pulmonary circulation in his thesis, De Motu Cordis [1]. Nevertheless, over a period of almost four centuries, limited emphasis was placed on the right ventricle (RV) and its role in the pathophysiology of heart disease. In fact, only in the past two decades have we begun to witness a constant increase in the attention paid by researchers and clinicians to the right heart chambers; this interest has been paralleled by the evolution of invasive and noninvasive cardiac imaging methods which have dramatically improved our understanding of the anatomy, physiology and pathophysiology of the right heart as well as pulmonary circulation in both congenital and acquired heart disease.

In this article we summarize the unique anatomical and physiological features of the RV, the pathophysiology underlying right heart failure and the emerging imaging modalities that aid in the assessment of RV function. Moreover, the prognostic impact of RV function under high preload and afterload conditions is discussed.

\section{Right Ventricular Anatomy}

In the human heart, the RV is anteriorly situated immediately behind the sternum. In the absence of congenital heart disease, it lies between the annulus of the tricuspid valve and the pulmonary valve. It consists of an inflow (sinus) and an outflow (conus) portion separated by the crista supraventricularis [2-4]. For the sake of standardization in cardiac imaging, it has been divided into an anterior, lateral and inferior segment, as well as

\section{KARGER}

Fax +41613061234

E-Mail karger@karger.ch

www.karger.com (c) 2012 S. Karger AG, Basel

$0008-6312 / 12 / 1214-0263 \$ 38.00 / 0$

Accessible online at:

www.karger.com/crd
Stavros Konstantinides, MD, FESC, Professor of Medicine

Department of Cardiology, University General Hospital

Democritus University of Thrace

GR-68100 Alexandroupolis (Greece)

Tel. +30 2551076 231, E-Mail skonst@ @ed.duth.gr 
Table 1. Anatomical features that differentiate the two ventricles

\begin{tabular}{lll}
\hline & RV & LV \\
\hline Shape & crescent-shaped/triangular & elliptic \\
EDV, $\mathrm{mm}^{3}$ & $75 \pm 13(49-101)$ & $66 \pm 12(44-89)$ \\
Mass, g/m ${ }^{2}$ BSA & $26 \pm 5(17-34)$ & $87 \pm 12(64-109)$ \\
Wall thickness, mm & $2-5$ & $7-11$ \\
\hline
\end{tabular}

BSA = Body surface area EDV = end-diastolic volume.

into a basal, mid and apical section [2-4]. Three major muscular bands are present in the RV: the parietal, septomarginal and moderator bands [5]. The following morphological characteristics further distinguish the RV from the left ventricle (LV):

- more apical hinge line of the septal leaflet of the tricuspid valve relative to the anterior leaflet of the mitral valve

- presence of a moderator band

- presence of more than three papillary muscles

- trileaflet configuration of the tricuspid valve with septal papillary attachments

- presence of coarse trabeculations.

These unique anatomic features are particularly helpful for recognizing the RV in the presence of congenital anomalies.

The RV has a more complex shape than the LV, appearing triangular when viewed from the side and semilunar (crescent-shaped) when viewed in cross section; its 3-dimensional shape is more complex, unlike the ellipsoid shape of the LV, a fact which reflects the low resistance in the pulmonary circulation [5]. The RV myocardium is thinner and its mass approximately one sixth of that of the LV, with an almost similar (slightly higher) end-diastolic volume (table 1) [5].

The RV wall is mainly composed of superficial and inner (deep) muscle layers; the fibers of the superficial layer are aligned circumferentially parallel to the atrioventricular groove, while the inner fibers are set longitudinally from base to apex. Importantly, the RV and LV myocardium are functionally interdependent: they share a common wall, the interventricular septum, have mutually encircling epicardial fibres and lie within the same intrapericardial space [5].

The blood supply to the RV varies according to the dominance of the coronary system. In a right-dominant system, the right coronary artery supplies the RV free wall in the posterior, right lateral and anterior segments of the heart. In addition, the right coronary artery supplies the inferior third of the interventricular septum. The RV is also supplied with blood from the left anterior descending artery [5]. In the absence of RV hypertrophy or pressure overload, epicardial right coronary artery flow occurs during both systole and diastole. However, beyond the RV marginal branches, blood flow is predominantly diastolic [6].

\section{Right Ventricular Physiology and Hemodynamics}

The primary function of the RV is to forward systemic venous return into the pulmonary circulation. In the normal human heart, the RV is connected in series with the LV and therefore ejects, on average, the same stroke volume $[5,6]$. RV contraction occurs in a sequential manner, as a peristaltic wave directed from the inflow to outflow tract. Deformation of the RV myocardium is the result of three contraction patterns: inward movement (free wall), longitudinal and circumferential; longitudinal shortening is the major contributor to overall RV contraction, while traction of the RV free wall secondary to LV contraction may contribute to as much as $40 \%$ of the stroke volume [7]. In contrast to the LV, twisting and rotational movements do not significantly contribute to RV performance $[6,7]$.

The physiological hemodynamics of the RV as opposed to the LV are summarized in table 2. In the absence of cardiac or pulmonary disease, right-sided pressures are significantly lower than left-sided pressures [8]. As a consequence, RV filling starts before and finishes after LV filling. RV systolic pressure rapidly exceeds the low pulmonary artery diastolic pressure and thus RV isovolumic relaxation time is shorter when compared to the $\mathrm{LV}$, and filling velocities are lower and with more pronounced respiratory variations. As is the case for the LV, RV performance depends on myocardial contractility, afterload and preload and is influenced by heart rhythm, intraventricular synchrony and ventricular interdependence [6].

Compared to the LV, the less muscular RV (table 1) is more sensitive to afterload alterations; in clinical practice, pulmonary vascular resistance is the most important determinant of RV afterload [6, 8].

In the normal heart, an increased RV preload improves myocardial contraction on the basis of the FrankStarling law. Nevertheless, excessive and prolonged RV volume overload reduces RV contractility and suppresses LV filling, ultimately leading to impaired global heart function [8]. Factors affecting RV preload include intra- 
Table 2. Physiological hemodynamics of the right as opposed to the left ventricle

\begin{tabular}{lll}
\hline & RV & LV \\
\hline Elastance $\left(\mathrm{E}_{\max }\right), \mathrm{mm} \mathrm{Hg} / \mathrm{ml}$ & $1.30 \pm 0.84$ & $5.48 \pm 1.23$ \\
PVR vs. SVR, dyn $\bullet \mathrm{sm}^{-5}$ & $70(20-130)$ & $1,100(700-1,600)$ \\
End-diastolic compliance & high & low \\
Ejection fraction, \% & $61 \pm 7(47-76)$ & $67 \pm 5(57-78)$ \\
Stroke work index, g/m ${ }^{2} \mathrm{BSA} /$ beat & $8 \pm 2(1 / 6$ of LV) & $50 \pm 20$ \\
Resistance to ischemia & high & low \\
Adaptation to disease & better for volume overload & better for pressure overload \\
\hline
\end{tabular}

$\mathrm{BSA}=$ Body surface area; $\mathrm{PVR}=$ pulmonary vascular resistance; $\mathrm{SVR}=$ systemic vascular resistance

vascular volume status, ventricular compliance, heart rate, LV filling pressure and pericardial pressure [8].

Ventricular interdependence refers to the concept that the size, shape and compliance of one ventricle affect the hemodynamic properties of the other [9]. The anatomical background of ventricular interdependence is (1) the presence of the interventricular septum, (2) the continuity of RV myocardial fibers and LV muscular layers and (3) the fact that both ventricles share the same pericardial cavity. Ventricular interdependence plays an essential part in the pathophysiology of RV dysfunction. Interdependence may affect both diastolic and systolic hemodynamic properties. Systolic ventricular interdependence is mediated mainly through the interventricular septum, while the pericardium contributes more to diastolic ventricular interdependence [9]. In acute RV pressure- or volume-overload states, dilatation of the RV increases intrapericardial pressure and shifts the interventricular septum to the left, altering LV geometry. As a consequence, the LV diastolicpressure volume curve shifts upward, leading to a decreased LV preload, increased LV end-diastolic pressure and consequently a low cardiac output [9].

\section{Pathophysiology of Right Ventricular Dysfunction and Failure}

The pathologic conditions and mechanisms that may lead to RV failure are summarized in figure 1 [10]. Right heart failure is becoming an increasingly frequent entity in current clinical practice as the prevalence of predisposing conditions in the population increases. In the majority of cases, RV function is compromised as a result of pressure overload, volume overload or a combination of both. Impaired RV contractility due to primary loss of
RV myocardium can also underlie right heart failure; however, conditions leading to RV myocardial damage are, with the exception of ischemia, rare and generally not confined to the right heart. Importantly, up to $25 \%$ of critically ill patients with acute lung injury and up to $50 \%$ of those with sepsis may develop acute right heart failure in the intensive care unit due to multiple mechanisms (fig. 2) [10].

Acute pulmonary embolism (PE) is the prototype of RV failure due to acute pressure overload [11]. Increased pulmonary artery pressure occurs in $60-70 \%$ of patients who have PE and roughly correlates with the anatomic severity of thromboembolic obstruction; in addition, vasoconstrictive factors released from the thrombus and reaction to hypoxia contribute to the increase in pulmonary vascular resistance [12-14]. Moreover, preexisting cardiac or pulmonary disease may enhance the hemodynamic impact of an acute thromboembolic event. Right ventricular dilatation and hypokinesis result from the interplay of these factors and may initiate a vicious circle of increased myocardial oxygen demand, myocardial ischemia or infarction and left ventricular preload reduction. Ultimately, the inability to maintain the cardiac index and arterial pressure leads to cardiogenic shock (fig. 3) $[15,16]$. Thus, RV dysfunction is the critical hemodynamic event and an important determinant of the clinical presentation, course and prognosis of $\mathrm{PE}$.

The pathophysiology of chronic pressure overload, which may lead to repeated episodes of acute decompensation, has been thoroughly studied in the setting of pulmonary arterial hypertension (PAH); at present, we can only assume that similar adaptive mechanisms underlie other high-afterload conditions. The first step in RV adaptation to pressure overload is myocardial hypertrophy and assumption of a spherical geometry in an effort to 
Fig. 1. Causes and mechanisms of right heart failure. ARVD = Arrhythmogenic right ventricular dysplasia; $\mathrm{ASD}=$ atrial septal defect; $\mathrm{CABG}=$ coronary artery bypass grafting surgery; $\mathrm{MV}=$ mitral valve; $\mathrm{PR}=$ pulmonary regurgitation; $\mathrm{RVOT}=$ right ventricular outflow tract; $\mathrm{SVC}=$ superior vena cava; $\mathrm{TR}=$ tricuspid regurgitation.

Fig. 2. Mechanisms of right heart failure in critically ill patients. IL = Interleukin; TNF $\alpha=$ tumor necrosis factor $\alpha$.
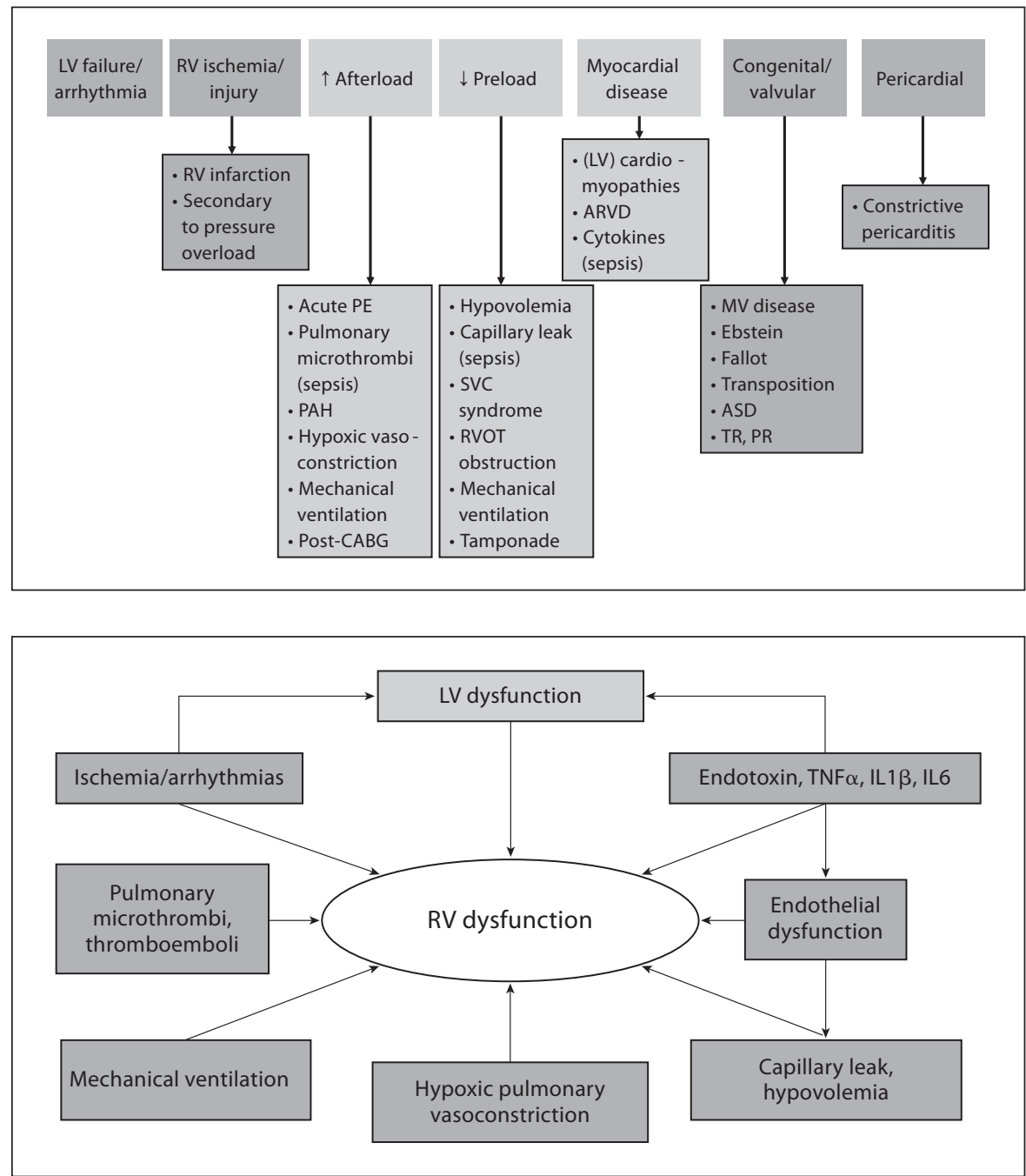

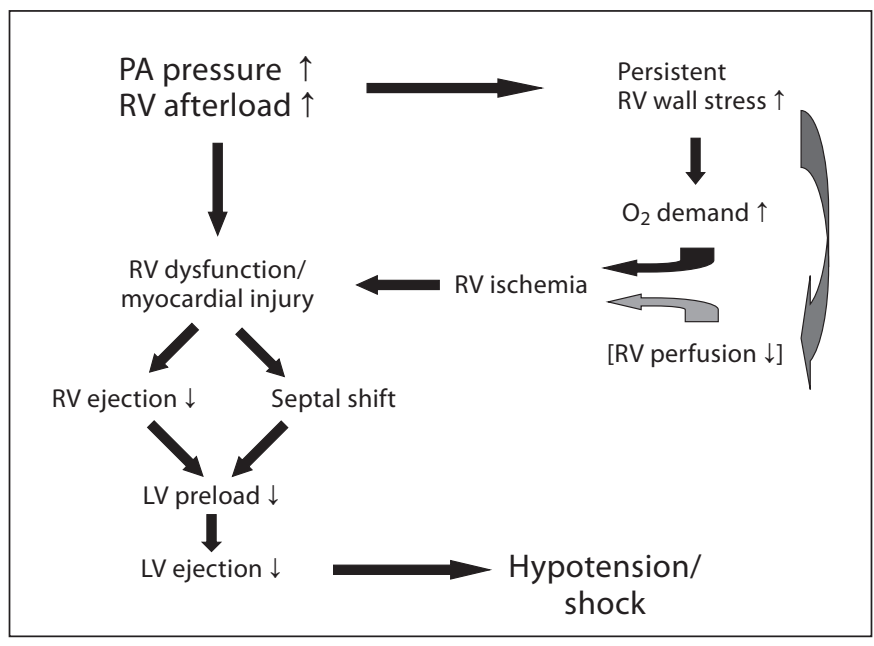

Fig. 3. Right heart failure due to acute pressure overload resulting from pulmonary embolism. $\mathrm{PA}=$ Pulmonary artery. reduce wall stress [17]. The increase in ventricular mass induced by an increase in afterload is predominantly the result of protein synthesis and an increase in cell size through the addition of sarcomeres in parallel. Protein synthesis in the cardiomyocytes is directly induced by stretch and enhanced by autocrine, paracrine and neurohormonal signals including activation of the renin-angiotensin and enhanced sympathetic activity [17, 18]. However, the RV is not capable of sustaining pressure overload over the long term. Cardiac contractile force decreases, probably due to functional and/or structural changes in cardiomyocytes. In fact, pressure-induced growth and proliferation of cardiomyocytes is accompanied by extracellular matrix synthesis, which influences diastolic and systolic function as well as ventricular morphology and provides the background for electrical instability $[19,20]$. The RV thus enters a vicious circle of 
increased wall tension, mismatch in myocardial oxygen demand and RV perfusion, furthering impairment in contractility and dilatation [17]. Maladaptive neurohormonal signaling, oxidative stress and inflammation may further contribute to the development of right heart failure [17].

The biochemical background of cardiomyocyte dysfunction under pressure overload is partly unclear. A constant finding in maladaptive cardiac remodeling is the alpha to beta isotype switch of the myosin heavy chains (MCH). In the normal adult RV, the alpha-MHC isotype makes up approximately one third of total MHC. The reduction in alpha-MHC content that is encountered in $\mathrm{PAH}$-associated right heart failure can have important functional consequences [21]: beta-MHC has lower adenosine triphosphatase activity than alpha-MHC, resulting in a significant decrease in systolic function [22]. Stressed hearts not only exhibit thick filament changes but also show increased expression of the thin filaments alpha-skeletal actin and alpha-smooth-muscle actin at the cost of alpha-cardiac actin [22-25]. However, the functional consequences of the alpha actin switch are not clear. The myocardial regulatory proteins troponin, tropomyosin and tropomodulin may also be involved in the pathobiology of right heart failure [26]. Phosphorylation of troponin $\mathrm{T}$ by protein kinase $\mathrm{C}$ inhibits troponin $\mathrm{T}$ binding to tropomyosin, which may contribute to the inhibition of maximal myofibrillar adenosine triphosphatase and contractile performance [26, 27]. Finally, abnormalities in enzymes and ion channels involved in myocyte stimulation/contraction, mitochondrial defects, depletion of myocardial adenosine triphosphate and modifications of myocardial substrate use (from fatty acids to glucose) have been implicated in maladaptive remodeling [18].

In addition to pressure effects, conditions including adult congenital heart disease and acquired valvular heart disease may place substantial volume loads on the RV. Such conditions include atrial septal defect, pulmonary artery regurgitation and tricuspid regurgitation. The RV responds to volume overload with an enhancement of contractile properties. Eccentric hypertrophy, during which terminally differentiated cardiomyocytes increase in size without undergoing cell division, is the initial adaptive response of the heart to volume overload. Initially, the hypertrophic response may serve to maintain cardiac function; however, prolonged hypertrophy becomes detrimental, resulting in cardiac dysfunction and heart failure via mechanisms similar to those operating under pressure overload as explained above. Overall, the RV tolerates volume overload better than pressure overload and may therefore stay well adapted for extended periods of time. For example, in volume overload associated with left-to-right shunt, the condition may remain relatively asymptomatic until pulmonary vasculopathy develops and the shunt reverses. In fact, even with established Eisenmenger's pathophysiology, the outcome of these patients is better than that of patients with idiopathic PAH [28-29].

\section{Invasive Assessment of Pulmonary Circulation Hemodynamics}

Despite the evolution of noninvasive cardiac imaging, cardiac catheterization remains the gold standard for the assessment of hemodynamic indices of the pulmonary circulation, by directly measuring pressures and indirectly estimating flow. Right heart catheterization confirms the presence of pulmonary hypertension, defines the underlying cause and provides prognostic information. For the measurement of cardiac output, both the thermodilution and Fick methods are reliable in most $\mathrm{PAH}$ patients in the absence of severe tricuspid regurgitation. Vasodilator challenge at the time of diagnosis provides prognostic information and aids in therapeutic decision-making [30].

Pulmonary hypertension is defined as an increase in mean pulmonary arterial pressure (PAP) $\geq 25 \mathrm{~mm} \mathrm{Hg}$ at rest as assessed by right heart catheterization. This value has been widely used in randomized controlled trials and registries of $\mathrm{PAH}$. Recent reevaluation of available data has shown that the normal mean PAP at rest is $14 \pm$ $3 \mathrm{~mm} \mathrm{Hg}$, with an upper limit (of normal) of $20 \mathrm{~mm} \mathrm{Hg}$ [30]; the significance of a mean PAP between 21 and 24 $\mathrm{mm} \mathrm{Hg}$ is less clear. With regard to the formerly proposed threshold of a mean PAP of $30 \mathrm{~mm} \mathrm{Hg}$ during exercise, the data to support this as a disease state are much less robust. In fact, healthy individuals can reach much higher PAP values upon exertion [30].

\section{Noninvasive Assessment of Right Ventricular Function}

Assessment of the RV is limited by its complex geometry and pronounced trabeculation that limit accurate endocardial visualization. The excellent accuracy and reproducibility of cardiac magnetic resonance imaging (MRI) is well established, making MRI the gold standard 
Table 3. Echocardiographic parameters for the assessment of RV function

\begin{tabular}{llcc}
\hline Echocardiographic index & Definition & Normal value & Reference \\
\hline RVOT-FS, mm & Change in RVOT diameter in diastole and systole & $61 \pm 13$ & {$[27]$} \\
RVFAC, $\%$ & Change in RV area between end-diastole and end-systole & $56 \pm 13$ & {$[28]$} \\
TAPSE, mm & Systolic motion of the lateral portion of the tricuspid ring & $20 \pm 2.8$ & {$[29]$} \\
RV MPI & towards the apex & $0.28 \pm 0.04$ & {$[30]$} \\
RV dp/dt, mm Hg/s & Ratio between RV isovolemic time and ejection time & $>1,000$ & {$[31]$} \\
\hline FS = Fractional shortening; MPI = myocardial performance index; RVFAC = RV fractional area change; & & \\
RVOT = right ventricular outflow tract.
\end{tabular}

technique for quantifying the RV chamber [31]. However, MRI is expensive and is only available in tertiary centers. Thus, echocardiography remains the most widely used modality for the assessment of RV size and function.

\section{Echocardiography}

A qualitative hemodynamic evaluation of the RV can be obtained from the parasternal short-axis view. In conditions associated with hemodynamic overload, the crescent RV shape is lost and the septum becomes flat. The LV assumes a nonspherical shape (D shape) that results in impaired LV filling and a decrease in cardiac output $[4,31]$.

The complex structure of RV does not allow geometrical assumptions on echocardiography; thus, only diameters and areas are used in the echocardiographic assessment of RV size. Determining the RV diameter in the parasternal long-axis view with a perpendicular line on the septum has been proven reproducible and less variable than the RVOT diameter measured in a parasternal shortaxis view [4]. From the same view, the limit of normal RV free wall thickness is $5 \mathrm{~mm}$, above which the ventricle is considered to be hypertrophied [4]. In the apical 4-chamber view, both the long- and short-axis diameters can be measured and the end-systolic and end-diastolic area can be determined. In normal individuals, RV area and midcavity diameter should be smaller than those of the LV, thus allowing a rough visual estimation of RV area. Assessment of the structure and architecture of the RV walls can identify features which suggest a particular etiology, such as RV infarction or arrhythmogenic RV cardiomyopathy. However, visual echocardiographic assessment is an inaccurate basis for identification of functional abnormalities. Novel quantitative echocardiographic techniques may help in more accurate evaluation [4].
The complex shape of the RV cavity also prohibits a quantitative approach to evaluating global RV function. Therefore, alternative parameters have been developed and validated using cardiac MRI and radionuclide ventriculography as a gold standard [32-37] (table 3). Among them, tricuspid annular plane systolic excursion (TAPSE) is most commonly used in clinical practice. TAPSE is easily measured using an M-mode cursor passed through the tricuspid lateral annulus in a 4-chamber view. This parameter measures the extent of systolic motion of the lateral portion of the tricuspid ring towards the apex. It has been reported to exhibit a good correlation with isotope-derived RV ejection fraction $[35,36]$.

Tissue Doppler imaging (TDI) is a technique that measures myocardial velocities, allowing a quantitative assessment of myocardial function during the entire cardiac cycle. Using TDI, several global and regional parameters such as timing, direction and amplitude of the velocity of the ventricular wall can be determined [38, 39]. The technique is less dependent on chamber geometry, and since no endocardial border definition is needed, it can be used in suboptimal echocardiographic images. Pulsed TDI is simple to use and has high temporal resolution $[38,39]$. It is limited by angle dependency and the fact that the sample volume is fixed and does not enable tracking of the whole region of interest. The latter limitation can be overcome with color TDI. Color TDI allows an offline analysis of several myocardial segments during the same cardiac cycle. Sample volumes can be set to follow cardiac motion. Color TDI values represent the median of the velocity spectrum $[39,40]$.

Doppler myocardial imaging-based techniques allow not only for the evaluation of myocardial velocities but also for extracting myocardial deformation parameters. Strain and strain rate represent deformation and defor- 
mation rate, respectively. Strain is defined as deformation of an object compared with its initial shape and is expressed as percentage. Strain rate or deformation rate defines the speed of the deformation. Strain rate correlates well with regional contractility and provides information which is less dependent on RV preload and afterload [40].

Another technique that can be employed for determining regional deformation is speckle tracking-based myocardial deformation imaging. Compared to Doppler techniques, speckle tracking techniques are angle-independent and more user-friendly. On the other hand, they are limited by the need for excellent image quality [41, 42].

Three-dimensional echocardiography could facilitate the study of RV morphology and function overcoming the complexity of RV shape [43,44]; it can determine volumes and, consequently, ejection fraction accurately without geometrical assumptions. Measurements of RV volumes and RV ejection fraction by real-time 3-dimensional echocardiography have been proved accurate and reproducible when compared with cardiac MRI [4346].

Despite promising results, the additive diagnostic or prognostic information that novel echocardiographic techniques may provide in clinical practice remains questionable. Certainly, these techniques need further validation in larger populations and in varied disease settings.

\section{Radionuclide Techniques}

Radionuclide techniques were developed and used as the gold standard of RV assessment in the pre-MRI era. They permit the determination of several parameters including ejection fraction, systolic ejection time, peak filling rates, peak ejection fraction and rate of contractility [47]. In radionuclide ventriculography, 99mTc-labeled erythrocytes are injected into the circulation. LV and RV function can be evaluated by first-transit studies (a type of beat-to-beat evaluation) or by gated (ECG-synchronized) blood pool imaging done over several minutes (multiple-gated acquisition). Both studies can be done during rest or after exercise. First-transit studies are fast and relatively easy, but multiple-gated acquisition provides better images and is currently more widely used. In first-transit studies, 8-10 cardiac cycles are imaged as the marker mixes with blood and passes through the central circulation. First-transit studies are ideal for assessing RV function and intracardiac shunts [47-49]. In multi-gated acquisition, imaging is synchronized with the $\mathrm{R}$ wave of the ECG. Multiple images are taken. Computer-assisted

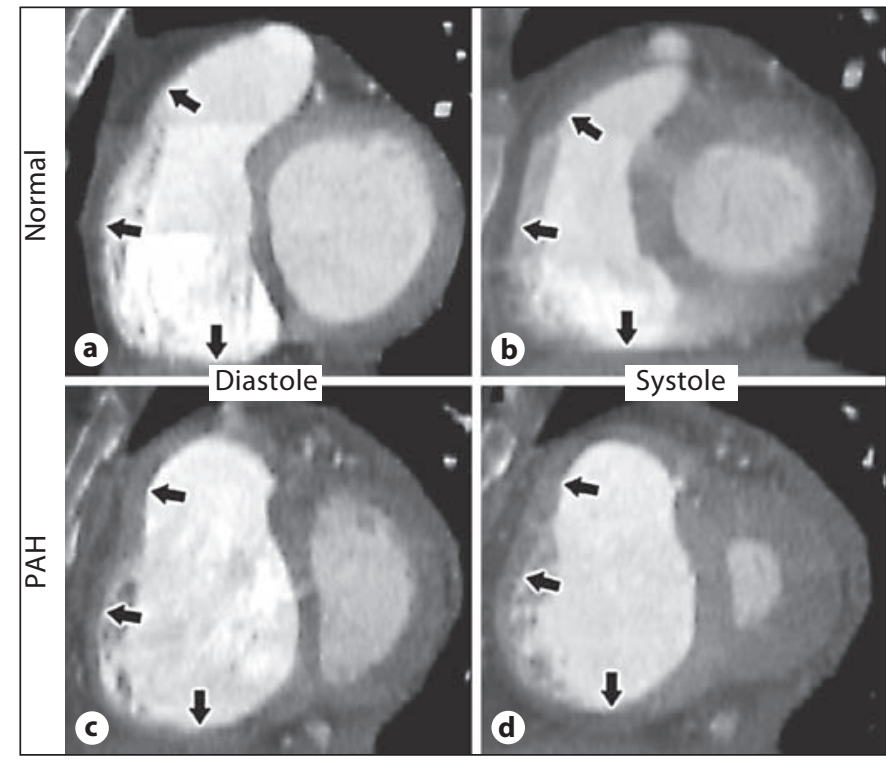

Fig. 4. Ventricular contraction and interdependence demonstrated by MRI [adapted from 66, with permission].

analysis generates an average blood pool configuration for each portion of the cardiac cycle and synthesizes the configurations into a continuous cinematic loop resembling a beating heart [47-49].

\section{Magnetic Resonance Imaging}

There have been major advances in MRI techniques in the past years including ECG gating and respiratory suppression, diminishing imaging artifacts and allowing automatic trace of RV volumes (fig. 4). The high accuracy and reproducibility of MRI measurements without the need of geometrical assumptions have made cardiac MRI the current gold standard for the study of RV size and function (table 4) [31, 50]. Moreover, using magnetic resonance angiography, a detailed 3-dimensional pulmonary angiogram can be obtained with injection of gadolinium in a peripheral vein allowing a global assessment of the pulmonary circulation.

Early studies using the phase-contrast technique and velocity-encoded MRI showed the feasibility of estimating right-side hemodynamics, but the accessibility and reproducibility of Doppler echocardiography has limited the use of these techniques in clinical practice. Recent advances in magnetic resonance angiography have made it possible to calculate regional quantitative perfusion parameters in the lung on the basis of 3-dimensional contrast-enhanced dynamic MR perfusion and principles of 
Table 4. Cardiovascular magnetic resonance-derived reference values for RV volumes, systolic function and mass

\begin{tabular}{|c|c|c|}
\hline & $\begin{array}{l}\text { Women, mean } \pm \text { SD } \\
(95 \% \mathrm{CI})\end{array}$ & $\begin{array}{l}\text { Men, mean } \pm \text { SD } \\
(95 \% \mathrm{CI})\end{array}$ \\
\hline RV mass (g) & $48 \pm 11(27,69)$ & $66 \pm 14(38,94)$ \\
\hline \multicolumn{3}{|l|}{ RV mass index } \\
\hline$\left(\mathrm{g} / \mathrm{m}^{2} \mathrm{BSA}\right)$ & $28 \pm 5(18,38)$ & $34 \pm 7(20,47)$ \\
\hline RV EDV (ml) & $126 \pm 21(84,168)$ & $163 \pm 25(113,213)$ \\
\hline \multicolumn{3}{|l|}{ RV EDV index } \\
\hline$\left(\mathrm{ml} / \mathrm{m}^{2} \mathrm{BSA}\right)$ & $73 \pm 9(55,92)$ & $83 \pm 12(60,106)$ \\
\hline RV ESV (ml) & $43 \pm 13(17,69)$ & $57 \pm 15(27,86)$ \\
\hline \multicolumn{3}{|l|}{ RV ESV index } \\
\hline$\left(\mathrm{ml} / \mathrm{m}^{2} \mathrm{BSA}\right)$ & $25 \pm 7(12,38)$ & $29 \pm 7(14,43)$ \\
\hline RV SV (ml) & $83 \pm 13(57,108)$ & $106 \pm 17(72,140)$ \\
\hline \multicolumn{3}{|l|}{ RV SV index } \\
\hline$\left(\mathrm{ml} / \mathrm{m}^{2} \mathrm{BSA}\right)$ & $48 \pm 6(36,60)$ & $54 \pm 8(38,70)$ \\
\hline RV EF (\%) & $66 \pm 6(54,78)$ & $66 \pm 6(53,78)$ \\
\hline
\end{tabular}

$\mathrm{BSA}=$ Body surface area $\mathrm{EDV}=$ end-diastolic volume; $\mathrm{EF}=$ ejection fraction; ESV = end-systolic volume; SV = stroke volume. Reference values adapted [65].

the indicator dilution theory. Such a direct and quantitative measurement would be desirable in the clinical assessment of PAH patients' response to therapy and could be a valuable end point in clinical trials. Moreover, although the quantification of vascular remodeling by angiography has not been validated in the assessment of $\mathrm{PAH}$, there is no doubt that MRI also possesses the advantage of providing information on RV global function and pulmonary vasculature physiology in a single setting [49-51].

\section{Positron Emission Tomography}

Positron emission tomography can quantify glucose uptake. Increased glucose uptake is usually associated with a glycolytic phenotype. A switch from mitochondria-based glucose oxidation to cytoplasm-based glycolysis, even in the absence of hypoxia, is detected in many disease states characterized by increased proliferation and suppressed apoptosis. This has also recently been reported in PAH-associated vascular remodeling [29]. In addition, a switch from fatty acid oxidation to glycolysis characterizes cardiac hypertrophy. It is thus possible that the degree of glucose uptake (as measured by the standardized uptake value of 18F-fluorodeoxy-glucose) might correlate with both the degree of vascular remodeling and RV function in PAH [52].

\section{Prognostic Impact of Right Ventricular Remodeling}

Over a century ago, it was hypothesized that left heart failure could affect function of the RV. Inversely, the impact of right heart function on LV performance and clinical outcomes still remains understudied [53]. As already emphasized, RV pressure overload may compromise LV function and lead to the clinical presentation of congestive heart failure. Furthermore, the failing RV is unable to maintain adequate $\mathrm{LV}$ preload, leading to the clinical presentation of low-output heart failure [54-55].

Even though RV performance, as assessed with the modalities discussed above, may per se remain a questionable therapeutic target in current clinical practice, it is already considered a strong prognostic clinical marker under various conditions of heart failure. In the setting of PAH, survival correlates inversely with hemodynamic parameters such as mean pulmonary arterial pressure, right atrial pressure and cardiac index [54, 55]. Moreover, treatment of $\mathrm{PAH}$ is not translated into better clinical outcomes unless accompanied by a parallel improvement in RV function [31]. More specifically, RV mass and size and right atrial pressure are better correlated with functional status and are better predictors of survival than pulmonary arterial pressure per se [55-57]. Accordingly, functional capacity assessed with the 6-minute walking distance correlates better with RV function than with pulmonary arterial pressure.

In the setting of left heart failure, there is consensus that evidence of RV dysfunction predicts poor outcome. Patients with ischemic cardiomyopathy and low LV ejection fraction who died during a 2-year follow up period had had a worse RV ejection fraction than survivors [58]. Accordingly, in the setting of acute myocardial infarction, it was demonstrated that the presence of a low radionuclide-determined RV ejection fraction, in addition to a low LV ejection fraction, has a $3 \times$ higher association with 1-year mortality than that of poor LV function on its own [59]. In patients with myocarditis, poor RV function as defined by a low TAPSE was associated with a greater likelihood of death or of transplantation than the presence of normal RV function [60]. In idiopathic dilated cardiomyopathy, the RV ejection fraction as assessed by cardiac catheterization was correlated linearly with echocardiographic LV ejection fraction, and emerged in a multivariate analysis as one of the strongest predictors of survival [61]. Multiple other indices of RV size and function have been correlated with the prognosis of patients with dilated cardiomyopathy including echo-derived diastolic RV chamber area and tricuspid annular plane systolic excur- 
sion [60-62]. Finally, RV performance has also been associated with better exercise tolerance in patients with advanced heart failure [63]. In fact, RV ejection fraction assessed by radionuclide angiography correlated better with functional capacity than LV ejection fraction [64].

\section{Conclusion}

Until recently, the RV received little attention in patients with acquired heart disease. Advances in imaging modalities have recently enabled us to accurately study RV physiology in health and disease. It has become apparent that the function of the RV strongly affects the function of the LV and vice versa. Disappointingly, the improvement in our knowledge in RV physiology has not yet resulted in advances in the clinical management of RV failure; indeed, specific therapeutic options for patients with clinically established RV failure are still scarce and treatment continues to be based on extrapolations from studies on LV failure. However, while awaiting progress in this field, clinicians should not come to think that assessment of RV function is futile. In this regard, it has to be kept in mind that multiple studies have demonstrated, beyond any doubt, that RV function is an important determinant of prognosis in heart failure irrespective of the etiological background. Therefore, RV function has to be considered as an important variable in therapeutic decision-making and should also be assessed as a marker of response to treatment in patients with heart failure.

\section{References}

1 Harvey W: Exercitatio Anatomica de Motu Cordis et Sanguinis in Animalibus. 1628.

2 Ho SY, Nihoyannopoulos P: Anatomy, echocardiography, and normal right ventricular dimensions. Heart 2006;92(suppl 1):i2-i13.

-3 Badano LP, Ginghina C, Easaw J, Muraru D, Grillo MT, Lancellotti P, Pinamonti B, Coghlan G, Marra MP, Popescu BA, De Vita S: Right ventricle in pulmonary arterial hypertension: haemodynamics, structural changes, imaging, and proposal of a study protocol aimed to assess remodelling and treatment effects. Eur J Echocardiogr 2010; 11:27-37.

4 Jurcut R, Giusca S, La Gerche A, Vasile S, Ginghina C, Voigt JU: The echocardiographic assessment of the right ventricle: what to do in 2010? Eur J Echocardiogr 2010; 11:81-96.

5 Haddad F, Hunt SA, Rosenthal DN, Murphy DJ: Right ventricular function in cardiovascular disease. I. Anatomy, physiology, aging, and functional assessment of the right ventricle. Circulation 2008;117:1436-1448.

6 Farb A, Burke AP, Virmani R: Anatomy and pathology of the right ventricle (including acquired tricuspid and pulmonic valve disease). Cardiol Clin 1992;10:1-21.

7 Petitjean C, Rougon N, Cluzel P: Assessment of myocardial function: a review of quantification methods and results using tagged MRI. J Cardiovasc Magn Reson 2005;7:501516.

8 MacNee W: Pathophysiology of cor pulmonale in chronic obstructive pulmonary disease: part one. Am J Respir Crit Care Med 1994;150: 833-852.
-9 Santamore WP, Dell'Italia LJ: Ventricular interdependence: significant left ventricular contributions to right ventricular systolic function. Prog Cardiovasc Dis 1998;40: 289-308.

10 Lahm T, McCaslin CA, Wozniak TC, Ghumman W, Fadl YY, Obeidat OS, Schwab K, Meldrum DR: Medical and surgical treatment of acute right ventricular failure. J Am Coll Cardiol 2010;56:1435-1446.

11 Torbicki A, Perrier A, Konstantinides S, Agnelli G, Galiè N, Pruszczyk P, Bengel F, Brady AJ, Ferreira D, Janssens U, Klepetko W, Mayer E, Remy-Jardin M, Bassand JP, ESC Committee for Practice Guidelines (CPG): Guidelines on the diagnosis and management of acute pulmonary embolism: the Task Force for the Diagnosis and Management of Acute Pulmonary Embolism of the European Society of Cardiology (ESC). Eur Heart J 2008;29:2276-2315.

12 Miller RL, Das S, Anandarangam T, Leibowitz DW, Alderson PO, Thomashow B, Homma S: Association between right ventricular function and perfusion abnormalities in hemodynamically stable patients with acute pulmonary embolism. Chest 1998;113:665-670.

13 McIntyre KM, Sasahara AA: The hemodynamic response to pulmonary embolism in patients without prior cardiopulmonary disease. Am J Cardiol 1971;28:288-294.

14 Smulders YM: Pathophysiology and treatment of haemodynamic instability in acute pulmonary embolism: the pivotal role of pulmonary vasoconstriction. Cardiovasc Res 2000;48:23-33.

15 Greyson C, Xu Y, Cohen J, Schwartz GG: Right ventricular dysfunction persists following brief right ventricular pressure overload. Cardiovasc Res 1997;34:281-288.
16 Schmitto JD, Doerge H, Post H, Coulibaly M, Sellin C, Popov AF, Sossalla S, Schoendube FA: Progressive right ventricular failure is not explained by myocardial ischemia in a pig model of right ventricular pressure overload. Eur J Cardiothorac Surg 2009;35:229234.

17 Skhiri M, Hunt SA, Denault AY, Haddad F: Evidence-based management of right heart failure: a systematic review of an empiric field. Rev Esp Cardiol 2010;63:451-471.

-18 Bogaard HJ, Abe K, Vonk Noordegraaf A, Voelkel NF: The right ventricle under pressure: cellular and molecular mechanisms of right-heart failure in pulmonary hypertension. Chest 2009;135:794-804.

19 Mann DL: Basic mechanisms of left ventricular remodeling: the contribution of wall stress. J Card Fail 2004;10(suppl 6):S202S206.

20 Janicki JS, Brower GL, Gardner JD, Forman MF, Stewart JA Jr, Murray DB, Chancey AL: Cardiac mast cell regulation of matrix metalloproteinase-related ventricular remodeling in chronic pressure or volume overload. Cardiovasc Res 2006;69:657-665.

21 Khan R, Sheppard R: Fibrosis in heart disease: understanding the role of transforming growth factor-beta in cardiomyopathy, valvular disease and arrhythmia. Immunology 2006;118:10-24.

22 Lowes BD, Minobe W, Abraham WT, Rizeq MN, Bohlmeyer TJ, Quaife RA, Roden RL, Dutcher DL, Robertson AD, Voelkel NF, Badesch DB, Groves BM, Gilbert EM, Bristow MR: Changes in gene expression in the intact human heart: downregulation of alpha-myosin heavy chain in hypertrophied, failing ventricular myocardium. J Clin Invest 1997;100:2315-2324. 
-23 Herron TJ, McDonald KS: Small amounts of alpha-myosin heavy chain isoform expression significantly increase power output of rat cardiac myocyte fragments. Circ Res 2002;90:1150-1152.

24 Chaponnier C, Gabbiani G: Pathological situations characterized by altered actin isoform expression. J Pathol 2004;204:386-395.

25 Bakerman PR, Stenmark KR, Fisher JH: Alpha-skeletal actin messenger RNA increases in acute right ventricular hypertrophy. Am J Physiol 1990;258:L173-L178.

26 VanBuren P, Okada Y: Thin filament remodeling in failing myocardium. Heart Fail Rev 2005;10:199-209.

-27 Adamcova M, Sterba M, Simunek T, Potacova A, Popelova O, Mazurova Y, Gersl V: Myocardial regulatory proteins and heart failure. Eur J Heart Fail 2006;8:333-342.

28 Hopkins WE, Ochoa LL, Richardson GW, Trulock EP: Comparison of the hemodynamics and survival of adults with severe primary pulmonary hypertension or Eisenmenger syndrome. J Heart Lung Transplant 1996;15:100-105.

29 Hopkins WE: The remarkable right ventricle of patients with Eisenmenger syndrome. Coron Artery Dis 2005;16:19-25.

30 Champion HC, Michelakis ED, Hassoun PM: Comprehensive invasive and noninvasive approach to the right ventricle-pulmonary circulation unit: state of the art and clinical and research implications. Circulation 2009;120:992-1007.

-31 Galiè N, Hoeper MM, Humbert M, Torbicki A, Vachiery JL, Barbera JA, Beghetti M, Corris P, Gaine S, Gibbs JS, Gomez-Sanchez MA, Jondeau G, Klepetko W, Opitz C, Peacock A, Rubin L, Zellweger M, Simonneau G, ESC Committee for Practice Guidelines (CPG): Guidelines for the diagnosis and treatment of pulmonary hypertension: the Task Force for the Diagnosis and Treatment of Pulmonary Hypertension of the European Society of Cardiology (ESC) and the European Respiratory Society (ERS), endorsed by the International Society of Heart and Lung Transplantation (ISHLT). Eur Heart J 2009;30: 2493-2537.

- 32 Katz J, Whang J, Boxt LM, Barst RJ: Estimation of right ventricular mass in normal subjects and in patients with primary pulmonary hypertension by nuclear magnetic resonance imaging. J Am Coll Cardiol 1993;21: 1475-1481.

33 Feigenbaum H, Armstrong W, Ryan T: Left atrium, right atrium, right ventricle; in Feigenbaum H, Armstrong W, Ryan T (eds.): Feigenbaum's Echocardiography. Philadelphia, Lippincott Williams \& Wilkins, 2005, pp 181-213.

-34 Lindqvist P, Henein M, Kazzam E: Right ventricular outflow-tract fractional shortening: an applicable measure of right ventricular systolic function. Eur J Echocardiogr 2003;4:29-35.
35 Lopez-Candales A, Dohi K, Rajagopalan N, Edelman K, Gulyasy B, Bazaz R: Defining normal variables of right ventricular size and function in pulmonary hypertension: an echocardiographic study. Postgrad Med J 2008;84:40-45.

36 Samad BA, Alam M, Jensen-Urstad K: Prognostic impact of right ventricular involvement as assessed by tricuspid annular motion in patients with acute myocardial infarction. Am J Cardiol 2002;90:778-781.

-37 Tei C, Dujardin KS, Hodge DO, Bailey KR, McGoon MD, Tajik AJ, Seward SB: Doppler echocardiographic index for assessment of global right ventricular function. J Am Soc Echocardiogr 1996;9:838-847.

-38 Stein PD, Sabbah HN, Anbe DT, Marzilli M: Performance of the failing and nonfailing right ventricle of patients with pulmonary hypertension. Am J Cardiol 1979;44:10501055.

39 Meluzín J, Spinarová L, Bakala J, Toman J, Krejcí J, Hude P, Kára T, Soucek M: Pulsed Doppler tissue imaging of the velocity of tricuspid annular systolic motion. A new, rapid, and non-invasive method of evaluating right ventricular systolic function. Eur Heart J 2001;22:340-348.

40 Kukulski T, Voigt JU, Wilkenshoff UM, Strotmann JM, Wranne B, Hatle L, Sutherland GR: A comparison of regional myocardial velocity information derived by pulsed and color Doppler techniques: an in vitro and in vivo study. Echocardiography 2000; 17:639-651.

-41 Greenberg NL, Firstenberg MS, Castro PL, Main M, Travaglini A, Odabashian JA, Drinko JK, Rodriguez LL, Thomas JD, Garcia MJ: Doppler-derived myocardial systolic strain rate is a strong index of left ventricular contractility. Circulation 2002;105:99-105.

42 Teske AJ, De Boeck BWL, Olimulder M, Prakken NH, Doevendans PAF, Cramer MJ: Echocardiographic assessment of regional right ventricular function: a head-to-head comparison between 2-dimensional and tissue Doppler-derived strain analysis. J Am Soc Echocardiogr 2008;21:275-283.

-43 Kjaergaard J, Petersen CL, Kjaer A, Schaadt BK, Oh JK, Hassager C: Evaluation of right ventricular volume and function by $2 \mathrm{D}$ and $3 \mathrm{D}$ echocardiography compared to MRI. Eur J Echocardiogr 2006;7:430-438.

44 Jenkins C, Chan J, Bricknell K, Strudwick M, Marwick TH: Reproducibility of right ventricular volumes and ejection fraction using real-time three-dimensional echocardiography: comparison with cardiac MRI. Chest 2007;131:1844-1851.

45 Lu X, Nadvoretskiy V, Bu L, Stolpen A, Ayres N, Pignatelli RH, Kovalchin JP, Grenier M, Klas B, Ge S: Accuracy and reproducibility of real-time three-dimensional echocardiography for assessment of right ventricular volumes and ejection fraction in children. J Am Soc Echocardiogr 2008;21:84-89.
46 Nageh MF, Kopelen HA, Zoghbi WA, Quinones MA, Nagueh SF: Estimation of mean right atrial pressure using tissue Doppler imaging. Am J Cardiol 1999;84:1448-1451.

-47 Massardo T, Jaimovich R, Lavados H, Gutiérrez D, Rodríguez JC, Saavedra JM, Alay R, Gatica H: Comparison of radionuclide ventriculography using SPECT and planar techniques in different cardiac conditions. Eur J Nucl Med Mol Imaging 2007;34:1735-1746.

48 Jain D, Zaret BL: Assessment of right ventricular function: role of nuclear imaging techniques. Cardiol Cli 1992;10:23-39.

49 Boxt LM, Katz J, Kolb T, Czegledy FP, Barst RJ: Direct quantitation of right and left ventricular volumes with nuclear magnetic resonance imaging in patients with primary pulmonary hypertension. J Am Coll Cardiol 1992;19:1508-1515.

50 Uematsu H, Levin DL, Hatabu H: Quantification of pulmonary perfusion with MR imaging: recent advances. Eur J Radiol 2001;37: 155-163.

-51 Ohno Y, Hatabu H, Murase K, Higashino T, Kawamitsu H, Watanabe H, Takenaka D, Fujii M, Sugimura K: Quantitative assessment of regional pulmonary perfusion in the entire lung using three-dimensional ultrafast dynamic contrast-enhanced magnetic resonance imaging: preliminary experience in 40 subjects. J Magn Reson Imaging 2004;20: 353-365.

52 de las Fuentes L, Herrero P, Peterson LR, Kelly DP, Gropler RJ, Davila-Roman VG: Myocardial fatty acid metabolism: independent predictor of left ventricular mass in hypertensive heart disease. Hypertension 2003;41: 83-87.

53 Yonekura Y, Brill AB, Som P, Yamamoto K, Srivastava SC, Iwai J, Elmaleh DR, Livni E, Strauss HW, Goodman MM, Knapp FF: Regional myocardial substrate uptake in hypertensive rats: a quantitative autoradiographic measurement. Science 1985;227: $1494-1496$.

54 Bernheim D: De I'asystolie veineuse dans l'hypertrophie du coeur gauche par stenose concomitante du ventricule droit. Rev Med 1910;39:785.

55 Michelakis ED, Wilkins M, Rabinovitch M: Emerging concepts and translational priorities in pulmonary arterial hypertension. Circulation 2008;118:1486-1495.

56 Voelkel NF, Quaife RA, Leinwand LA, Barst RJ, McGoon MD, Meldrum DR, Dupuis J, Long CS, Rubin LJ, Smart FW, Suzuki YJ, Gladwin M, Denholm EM, Gail DB: Right ventricular function and failure: report of a National Heart, Lung, and Blood Institute Working Group on Cellular and Molecular Mechanisms of Right Heart Failure. Circulation 2006;114:1883-1891.

57 Ghofrani A, Wilkins MW, Rich S: Uncertainties in the diagnosis and treatment of pulmonary arterial hypertension. Circulation 2008;118:1195-1201. 
58 Polak JF, Holman L, Wynne J, Colucci WS: Right ventricular ejection fraction: an indicator of increased mortality in patients with congestive heart failure associated with coronary artery disease. J Am Coll Cardiol 1983; 2:217-224.

59 Shah PK, Maddahi J, Staniloff HM, Ellrodt AG, Pichler M, Swan HJ, Berman DS: Variable spectrum and prognostic implications of left and right ventricular ejection fractions in patients with and without clinical heart failure after acute myocardial infarction. Am J Cardiol 1986;58:387-393.

60 Mendes LA, Dec GW, Picard MH, Palacios IF, Newell J, Davidoff R: Right ventricular dysfunction: an independent predictor of adverse outcome in patients with myocarditis. Am Heart J 1994;128:301-307.
61 Juilliere Y, Barbier G, Feldmann L, Grentziger A, Danchin N, Cherrier F: Additional predictive value of both left and right ventricular ejection fractions on long-term survival in idiopathic dilated cardiomyopathy. Eur Heart J 1997; 18:276-280.

62 Karatasakis GT, Karagounis LA, Kalyvas PA, Manginas A, Athanassopoulos GD, Aggelakas SA, Cokkinos DV: Prognostic significance of echocardiographically estimated right ventricular shortening in advanced heart failure. Am J Cardiol 1998;82:329334.

63 Di Salvo TG, Mathier M, Semigran MJ, Dec GW: Preserved right ventricular ejection fraction predicts exercise capacity and survival in advanced heart failure. J Am Coll Cardiol 1995;25:1143-1153.
64 Baker BJ, Wilen MM, Boyd CM, Dinh H, Franciosa JA: Relation of right ventricular ejection fraction to exercise capacity in chronic left ventricular failure. Am J Cardiol 1984;54:596-599.

65 Maceira AM, Prasad SK, Khan M, Pennell DJ: Reference right ventricular systolic and diastolic function normalized to age, gender and body surface area from steady-state free precession cardiovascular magnetic resonance. Eur Heart J 2006; 27:2879-2888.

66 Simon MA: Right ventricular adaptation to pressure overload. Curr Opin Crit Care 2010; 16:237-243. 